\title{
BEHAVIOUR OF INTERFACES BETWEEN CARBON FIBRE REINFORCED POLYMER AND GRAVEL SOILS
}

\author{
I. Lavanya ${ }^{1}$, R. Prabha ${ }^{2}$, M. Murugan ${ }^{3}$ \\ ${ }^{1}$ Undergraduate Student, Civil Department, V V College Of Engineering, Tamil Nadu, India \\ ${ }^{2}$ Undergraduate Student, Civil Department, $V$ V College Of Engineering, Tamil Nadu, India \\ ${ }^{3}$ Assistant Professor, Civil Department, V V College of Engineering, Tamil Nadu, India
}

\begin{abstract}
Friction between soil and foundation materials is of major significance to make a good estimation of frictional resistance between soil and substructures. Soil-substructure interaction problems including retaining walls, deep foundations, soil samplers, soil and geo-membrane interface strength, and the stability of mechanically stabilized structures. Fibre Reinforced Polymer (FRP) is a synthetic material and can be effectively used for strengthening of soils and substructures retrofitting. This paper describes the results of an experimental study of interface friction between Carbon Fibre Reinforced Polymer (CFRP) wrapped concrete specimens and gravel soils. The experimental results showed that there is a significant decrease in the angle of interface friction with CFRP wrapping.
\end{abstract}

Keywords: Direct shear test, gravel soils, internal friction angle, interface friction angle, CFRP.

\section{INTRODUCTION}

The understanding of friction at soil-solid surface contact is an important task not only for traditional foundation structures such as piles, micro piles, anchors, etc., but also for more recent soil reinforcement techniques such as reinforced earth, soil nailing, etc. Foundation engineering has historically involved the use of wood, concrete, steel, or a combination of these materials. Many of the conventional materials have been found to deteriorate with time. It is essential to retrofit the deteriorated substructures for the better performance under external loads. In response to growing needs for strengthening and rehabilitation of structures, many researchers have considered application of Fiber-reinforced Polymer (FRP) (laminated) sheets/strips as an effective strengthening and rehabilitation method. FRP sheets/strips have many advantageous engineering characteristics such as high strength-to-.FRP weight and stiffness-to-weight ratio, corrosion resistance, easy application and construction has limited use in geotechnical engineering applications to date, due to lack of information regarding the behavior of systems that include these materials. To provide some insight into the interface behavior between FRP and gravels, an experimental study was performed to evaluate the importance of various factors. The behavior of the FRP-gravel interfaces was also compared with the concrete-gravel interfaces. Tsubakihara et al.[1] conducted laboratory tests on friction between cohesive soils and mild steel; experimental results indicate that the friction is depends on the roughness of steel. Frost and Han[2] conducted experiments to investigate the behavior of sand-FRP interfaces and concluded that interface shear behavior between FRP composites and granular materials depended on the relative roughness (surface roughness/particle mean size), the normal stress level, the initial density of the soil mass, and the angularity of the particles. Hammoud Boumekik[3] studied the interfacial shearing between cohesive soils and solid materials. The results show that the shearing resistance at the interface depends on the interface roughness, as well as on the properties of soils. Gireesha and Muthukkumaran[4] studied the interface friction angle of different structural materials (concrete, steel and wood) against well and poorly graded sands with varying relative density. The experimental results showed that both internal and interface friction angle decreases with increasing relative density of both well and poorly graded sand.

\section{SOIL CHARACTERISTICS}

Two types of gravel soils were used for this experimental study. The Engineering properties of the gravel soils are listed in Table.1. The gravel soils were classified as well and poorly graded according to IS: $1498-1970$.

Table 1 Engineering properties of the gravel soils used in the study

\begin{tabular}{|l|l|l|}
\hline Soil Property & $\begin{array}{l}\text { Well graded } \\
\text { gravel }\end{array}$ & $\begin{array}{l}\text { Poorly } \\
\text { graded } \\
\text { gravel }\end{array}$ \\
\hline Grain size analysis: & $2.30 \mathrm{~mm}$ & $2.4 \mathrm{~mm}$ \\
Effective size, $\mathrm{D}_{10}$ & 4.37 & 3.875 \\
Coefficient of uniformity, $\mathrm{C}_{\mathrm{u}}$ & 1.17 & 0.952 \\
Coefficient of curvature, $\mathrm{C}_{\mathrm{c}}$ & $\mathrm{GW}$ & $\mathrm{GP}$ \\
Classification (unified) & 2.64 & 2.63 \\
\hline Specific gravity, $\mathrm{G}_{\mathrm{s}}$ & & \\
\hline Dry unit weight: & $1.956 \mathrm{~g} / \mathrm{cm}^{3}$ & 1.935 \\
Maximum, $(\mathrm{max})$ & $1.623 \mathrm{~g} / \mathrm{cm}^{3}$ & $\mathrm{~g} / \mathrm{cm}^{3}$ \\
Minimum, $\gamma_{\mathrm{d}}(\mathrm{min})$ & $1.782 \mathrm{~g} / \mathrm{cm}^{3}$ & 1.601 \\
Test, $\gamma_{\mathrm{d}}(\mathrm{test})$ & \multicolumn{2}{|l}{$\mathrm{g} / \mathrm{cm}^{3}$} \\
\hline
\end{tabular}




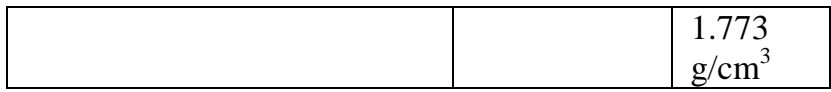

\section{TESTING METHODOLOGY}

For the interface frictional test, five concrete specimens of size $6 \mathrm{~cm} \times 6 \mathrm{~cm} \times 1.4 \mathrm{~cm}$ we prepared. The concrete specimens were prepared by first mixing the sand and cement, adding water and mixing gradually, subsequently filling the prepared boxes with concrete. The remoulded specimens were cured in water. After sufficient curing, one specimen was tested without any CFRP wrapping and remaining four specimens were wrapped with CFRP material (Fig. 1)

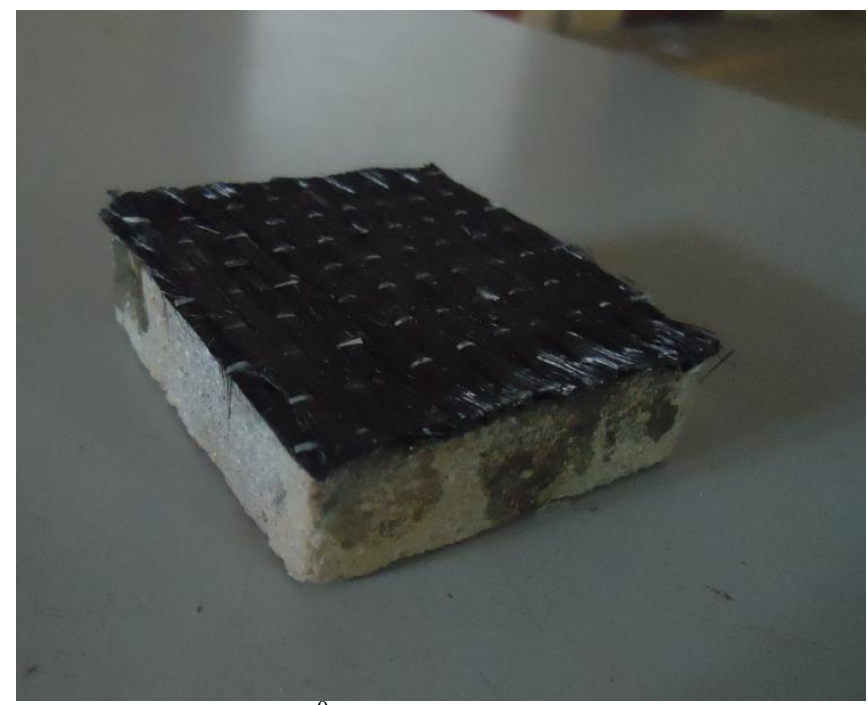

Fig. 1 a $0^{0}$ CFRP wrapped specimen

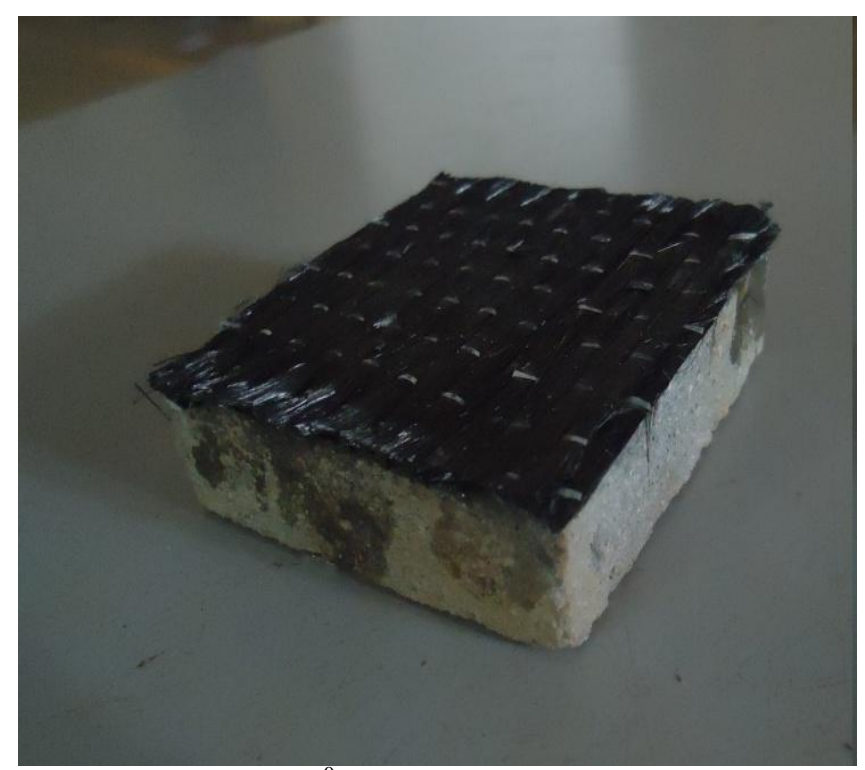

Fig. 1b $90^{\circ}$ CFRP wrapped specimen

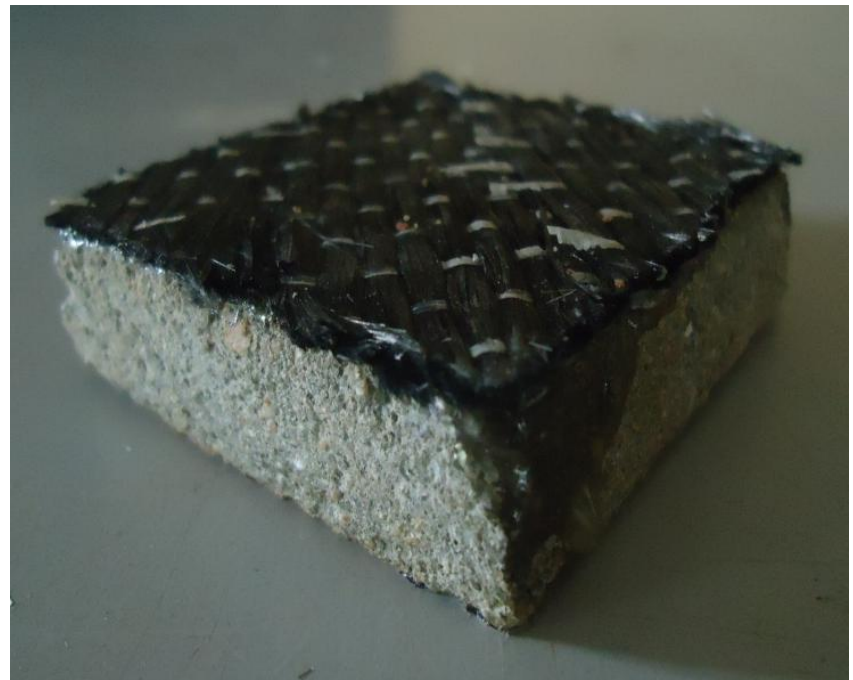

Fig. 1c $45^{0}$ CFRP wrapped specimen

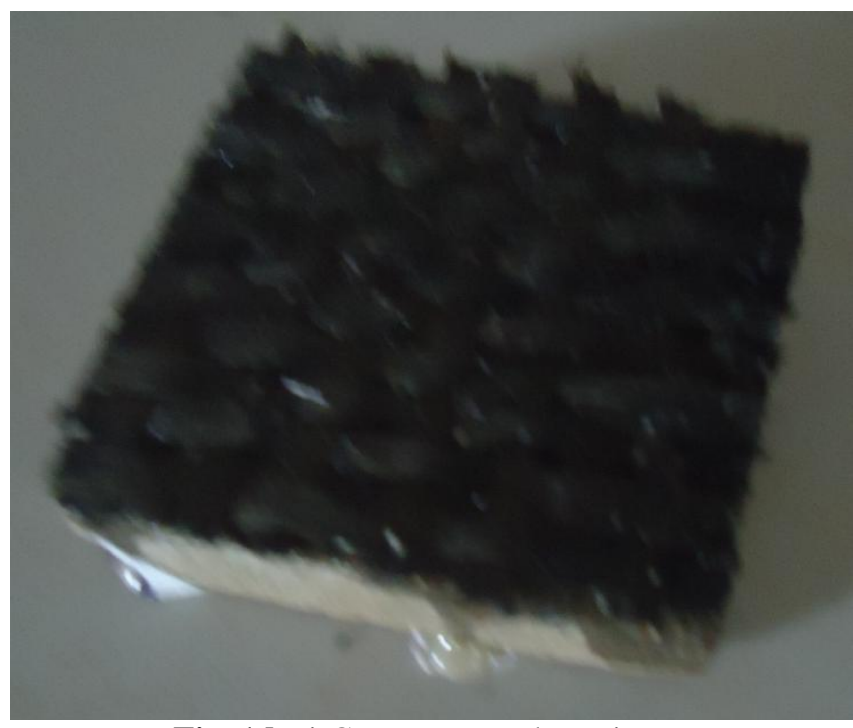

Fig. 1d Bi-CFRP wrapped specimen

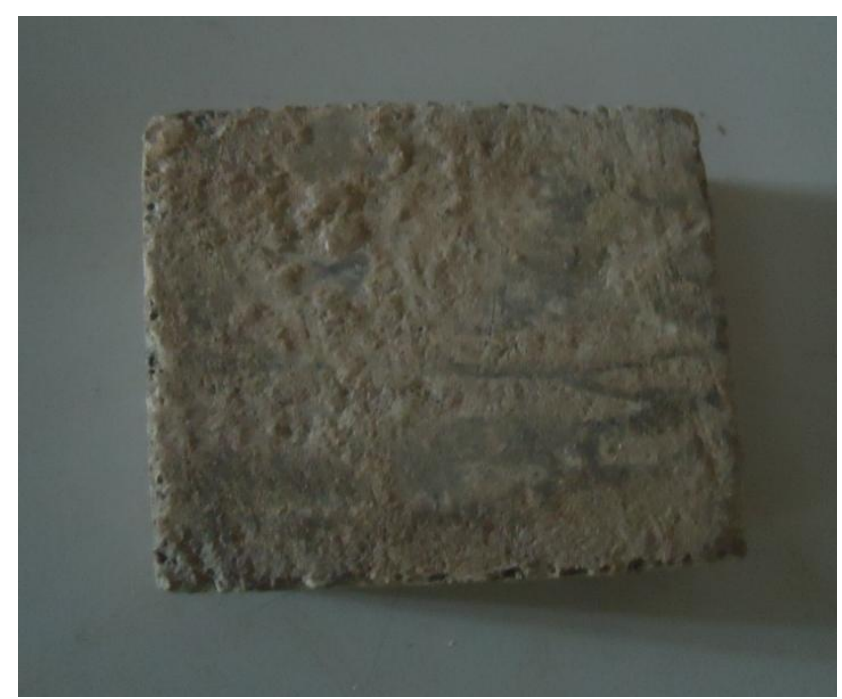

Fig. 1e Concrete specimen

Fig.1 Concrete specimens used in this study 
Direct shear test was conducted for these specimens with gravels. The specimens were placed in the lower half of the direct shear box and the upper half of the shear box was filled with gravels at predetermined density. When a shearing force is applied to the lower box through the geared jack, the movement of the lower part of the box is transmitted through the specimen to the upper part of the box and hence on the proving ring. The deformation of proving ring indicates the shear force. The horizontal displacement during the shearing process is measured by mounting a dial gauge at the top of the box. Samples were sheared at $1.25 \mathrm{~mm} / \mathrm{min}$. For each tests, four normal stress $0.5 \mathrm{~kg} / \mathrm{cm}^{2}, 1.0 \mathrm{~kg} / \mathrm{cm}^{2}, 1.5 \mathrm{~kg} / \mathrm{cm}^{2}$ and $2.0 \mathrm{~kg} / \mathrm{cm}^{2}$ were applied. A typical shear box arrangement is shown in Fig.2.

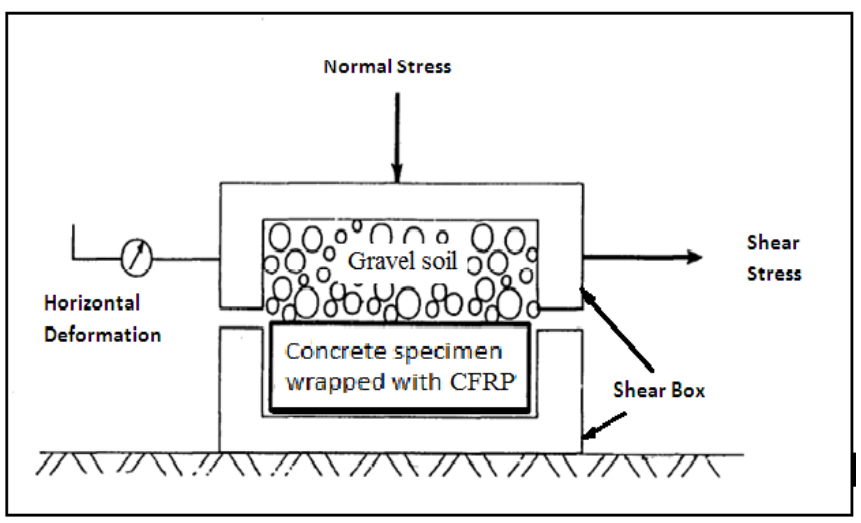

Fig.2 Test set up for interface friction measurement

\section{TEST RESULTS AND DISCUSSIONS}

The results obtained for well and poorly graded gravels under different normal stresses were analysed to obtain the required shear strength parameters. The obtained shear strength parameters are presented in Table 2.

Table 2 Shear strength parameter:

\begin{tabular}{|l|l|l|l|}
\hline \multirow{2}{*}{$\begin{array}{l}\text { Sl. } \\
\text { No }\end{array}$} & \multirow{3}{|c|}{$\begin{array}{l}\text { Angle } \\
\text { internal/interface } \\
\text { friction }\end{array}$} \\
\cline { 3 - 4 } & & $\begin{array}{l}\text { Type of interaction } \\
\text { graded } \\
\text { gravel }\end{array}$ & $\begin{array}{l}\text { Poorly } \\
\text { graded } \\
\text { gravel }\end{array}$ \\
\hline 1 & Gravel - Gravel & $38.21^{\circ}$ & $36.48^{\circ}$ \\
\hline 2 & Gravel - Concrete & $36.92^{\circ}$ & $34.94^{\circ}$ \\
\hline 3 & Gravel $-0^{0}$ CFRP & $33.12^{\circ}$ & $31.82^{\circ}$ \\
\hline 4 & Gravel $-45^{\circ}$ CFRP & $34.84^{\circ}$ & $33.56^{\circ}$ \\
\hline 5 & Gravel $-90^{\circ}$ CFRP & $35.68^{\circ}$ & $34.18^{\circ}$ \\
\hline 6 & Gravel - Bi-CFRP & $34.36^{\circ}$ & $33.35^{\circ}$ \\
\hline
\end{tabular}

Note:

- $\quad 0^{\circ} \mathrm{CFRP}$ - Fibres are parallel to shear

- $45^{\circ} \mathrm{CFRP}$ - Fibres are inclined to shear at $45^{\circ}$

- $\quad 90^{\circ} \mathrm{CFRP}$ - Fibres are perpendicular to shear

- Bi-CFRP - Fibres are parallel and perpendicular to shear.

\subsection{Internal/Interface Friction Angle for well}

\section{Graded Gravel}

Examining the data obtained from direct shear test, it could be seen that, in general, there was a decrease in the angle of interface friction between well graded gravel and CFRP wrapped concrete specimens (Ref.Fig.3).

- Angle of interface friction between well graded gravel and $0^{\circ}$ CFRP wrapped concrete specimen was $10.29 \%$ lower than the angle of interface friction between well graded gravel and concrete specimen without CFRP wrapping.

- Angle of interface friction between well graded gravel and $45^{\circ}$ CFRP wrapped concrete specimen was $5.63 \%$ lower than the angle of interface friction between well graded gravel and concrete specimen without CFRP wrapping.

- Angle of interface friction between well graded gravel and $90^{\circ}$ CFRP wrapped concrete specimen was $3.36 \%$ lower than the angle of interface friction between well graded gravel and concrete specimen without CFRP wrapping.

- Angle of interface friction between well graded gravel and Bi-CFRP wrapped concrete specimen was $6.93 \%$ lower than the angle of interface friction between well graded gravel and concrete specimen without CFRP wrapping.

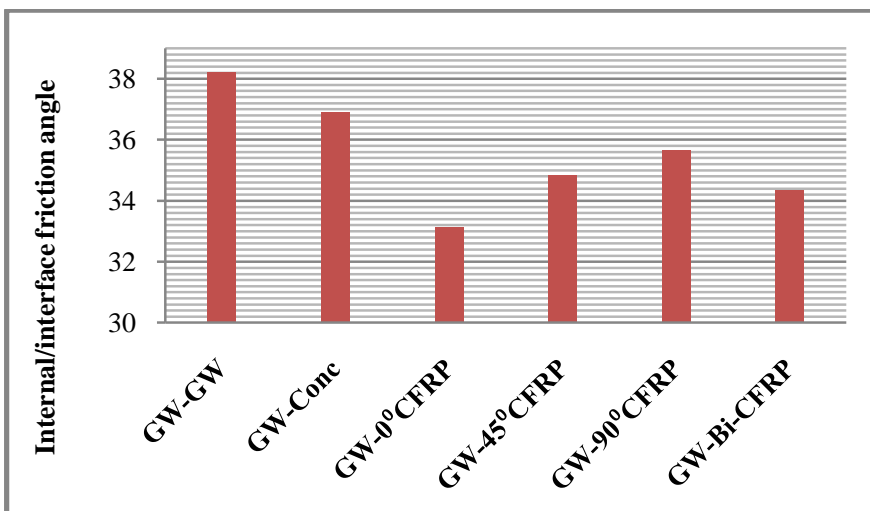

Fig.3: Internal/interface friction angle for well graded gravel

\subsection{Internal/Interface Friction Angle for Poorly}

\section{Graded Gravel}

Examining the data obtained from direct shear test, it could be seen that, in general, there was a decrease in the angle of interface friction between poorly graded gravel and CFRP wrapped concrete specimens (Ref.Fig.4).

- Angle of interface friction between poorly graded gravel and $0^{\circ}$ CFRP wrapped concrete specimen was $8.93 \%$ lower than the angle of interface friction between poorly graded gravel and concrete specimen without CFRP wrapping.

- Angle of interface friction between poorly graded gravel and $45^{\circ}$ CFRP wrapped concrete specimen was $3.95 \%$ lower than the angle of interface friction 
between poorly graded gravel and concrete specimen without CFRP wrapping.

- Angle of interface friction between poorly graded gravel and $90^{\circ}$ CFRP wrapped concrete specimen was $2.18 \%$ lower than the angle of interface friction between poorly graded gravel and concrete specimen without CFRP wrapping.

- Angle of interface friction between poorly graded gravel and Bi-CFRP wrapped concrete specimen was $4.55 \%$ lower than the angle of interface friction between poorly graded gravel and concrete specimen without CFRP wrapping.

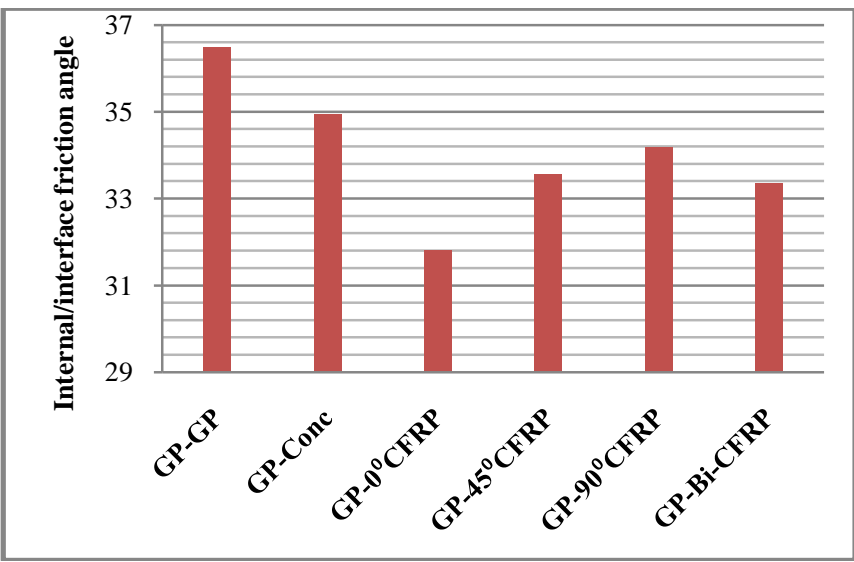

Fig.4. Internal/interface friction angle for poorly graded gravel

\section{CONCLUSIONS}

The friction between soil and construction materials is a major problem in soil-structure interaction study. Direct shear tests were conducted to investigate the interface angle of friction between well and poorly graded gravel and CFRP wrapped concrete specimens. Examining the data obtained from direct shear test, it could be seen that, in general, there was a decrease in the angle of interface friction with CFRP wrapping. Angle of interface friction between well graded gravel and CFRP wrapped concrete specimens were higher than the angle of interface friction between poorly graded gravel and CFRP wrapped concrete specimens. Higher angle of interface friction between gravel and $90^{\circ}$ CFRP wrapped (Fibres are perpendicular to shear) concrete specimens than $0^{\circ}, 45^{\circ}$ and bi-directionally CFRP wrapped concrete specimens. Further research might be required to have better understanding of shear strength parameters between soil and construction materials which could be proposed and used as a reference for design engineers to solve various geotechnical problems.

\section{REFERENCES}

[1]. Tsubakihara, Y., Kishida, H., and Nishiyama, T. (1993), Friction between Cohesive Soils and Steel, Geotechnical Society, Soils and Foundations, Vol.33, No.2, June 1993, pp145-156.

[2]. Frost, J. D., and Han J. (1999), Behavior of Interfaces between Fiber-Reinforced Polymers and Sands, Journal of
Geotechnical and Geo-Environmental Engineering, August 1999, pp 633-640.

[3]. Hammoud, F., and Boumekik, A. (2006), Experimental Study of the Behavior of Interfacial Shearing between Cohesive Soils and Solid Materials at Large Displacement, Asian Journal of Civil Engineering (Building and Housing), Volume 07, No 01, pp 63-80.

[4]. Gireesha, N. T., and Muthukkumaran, K. (2011), Study on soil structure interface strength property, International Journal of Earth Sciences and Engineering, Volume 04, No 06 SPL, October 2011, pp 89-93. 